\title{
The Contributions to Virulence of the Effectors Eop1 and DspE Differ Between Two Clades of Erwinia tracheiphila Strains
}

\author{
Olakunle I. Olawole, Qian Liu, Chiliang Chen, Mark L. Gleason, and Gwyn A. Beattie ${ }^{\dagger}$ \\ Department of Plant Pathology and Microbiology, lowa State University, Ames, IA, U.S.A.
}

Accepted 3 September 2021.

\begin{abstract}
Strains of Erwinia tracheiphila, causal agent of bacterial wilt of cucurbits, are divided into distinct clades. Et-melo clade strains wilt Cucumis spp. but not Cucurbita spp., thus exhibiting host specificity, whereas $E t-C 1$ clade strains wilt $C u c u r$ bita spp. more rapidly than Cucumis melo, thus exhibiting a host preference. This study investigated the contribution of the effector proteins Eop1 and DspE to E. tracheiphila pathogenicity and host adaptation. Loss of eop1 did not enable Et-melo strains to infect squash (Cucurbita pepo) or an Et-C1 strain to induce a more rapid wilt of muskmelon (Cucumis melo), indicating that Eop1 did not function in host specificity or preference as in the related pathogen $E$. amylovora. However, overexpression of eopl from Et-melo strain MDCuke but not from $\mathrm{Et}$-Cl strain BHKY increased the virulence of a BHKY eop1 deletion mutant on muskmelon, demonstrating that the Eop1 variants in the two clades are distinct in their virulence functions. Loss of $d s p E$ from Et-melo strains reduced but did not eliminate virulence on hosts muskmelon and cucumber, whereas loss of $d s p E$ from an $E t-C 1$ strain eliminated pathogenicity on hosts squash, muskmelon, and cucumber. Thus, the centrality of DspE to virulence differs in the two clades. Et-melo mutants lacking the chaperone DspF exhibited similar virulence to mutants lacking DspE, indicating that DspF is the sole chaperone for DspE in E. tracheiphila, unlike in E. amylovora. Collectively, these results provide the first functional evaluation of effectors in E. tracheiphila and demonstrate clade-specific differences in the roles of Eop1 and DspE.
\end{abstract}

Keywords: bacterial pathogenesis, chaperone, cucurbit, effector, host-specificity, muskmelon, phytopathogenic bacteria, squash, type III secretion system, wilt, xylem

${ }^{\dagger}$ Corresponding author: G. A. Beattie; gbeattie@iastate.edu

Funding: This work was supported by funding from the Iowa State University (ISU) Presidential Fellowship and the ISU College of Agriculture and Life Sciences.

*The $\boldsymbol{e}$-Xtra logo stands for "electronic extra" and indicates that supplementary materials are published online.

The author(s) declare no conflict of interest.

(c) (1) Copyright $\odot 2021$ The Author(s). This is an open access article distributed under the CC BY 4.0 International license.
Erwinia tracheiphila is a xylem pathogen that causes bacterial wilt of cucurbits in the Cucurbita (squash and pumpkin) and Cucumis (muskmelon and cucumber) genera (Smith 1911). This pathogen is transmitted by striped and spotted cucumber beetles (Acalymma vittatum and Diabrotica undecimpunctata, respectively). When these beetles feed on leaves or flowers of cucurbits, they can deposit E. tracheiphila-infested frass onto fresh feeding wounds, allowing bacterial entry into the xylem (Rojas et al. 2015). E. tracheiphila cells multiply in the xylem, producing exopolysaccharides that likely help obstruct the vascular system; this can lead to wilt, collapse, and eventual plant death. Cucurbits are grown throughout the United States but bacterial wilt is restricted to the Northeastern and Midwestern regions; these regions account for approximately $68 \%$ of the nation's total cultivated cucurbit acreage (Rojas et al. 2015). Bacterial wilt is managed primarily by frequent insecticide applications to reduce the cucumber beetle populations, although alternative management strategies include the deployment of row tunnels to prevent beetle feeding (Sánchez et al. 2015) and perimeter trap crops to lure beetle vectors to an alternate crop (Cavanagh et al. 2009; Weber 2018).

E. tracheiphila strains fall into distinct clades based on their genetics. In all, 69 strains were initially separated into two groups based on repetitive element sequence-based (rep)-PCR fingerprints (Rojas et al. 2013), with a subsequent study separating 88 strains into three phylogenetic clades based on comparative genomics of whole-genome sequences (Shapiro et al. 2018). The rep-PCR-based groups generally correspond to the phylogenetic clades designated Et-melo and Et-Cl and exhibit host-specific virulence patterns. Et-melo strains induce rapid wilt on the Cucumis spp. muskmelon (Cucumis melo) and cucumber (C. sativa) but do not induce wilt on Cucurbita spp. (Nazareno and Dumenyo 2015; Vrisman et al. 2016), although a study in the greenhouse reported induction of nonlethal, localized wilt symptoms on squash (Cucurbita pepo) (Shapiro et al. 2018). In contrast, Et-Cl strains induce wilt on Cucumis and Cucurbita spp. but induce a more rapid wilt on squash than on muskmelon (Nazareno and Dumenyo 2015; Rojas et al. 2013; Shapiro et al. 2018; Vrisman et al. 2016). Thus, Et-Cl strains demonstrate a greater aggressiveness to, or a host preference for, squash over muskmelon. A third clade, Et-C2, contains recently isolated strains that exhibit the same host preference as the Et-Cl strains but originated from a more localized geographic range (Shapiro et al. 2018). The host adaptation of these clades may be even more marked in the field, because all of the Et-melo strains in current collections were isolated from muskmelon or cucumber, and all of the Et-C1 and Et-C2 strains were isolated from squash or cucumber (Rojas et al. 2013; Shapiro et al. 2018). 
We are interested in understanding the factors contributing to the pathogenicity and host adaptation of E. tracheiphila strains. Like many gram-negative phytopathogens, E. tracheiphila has a type III secretion system (T3SS), which is a membranespanning structure that enables the secretion and delivery of bacterial effector proteins into host cells. These effector proteins are often key factors in pathogenicity and host specificity. E. tracheiphila strains share several effectors with the well-characterized and related pathogen, E. amylovora. E. amylovora secretes only a limited repertoire of effectors (Yuan et al. 2020), of which two, Eop1 and DspE, have been particularly well studied. Like E. tracheiphila, E. amylovora strains fall into groups that differ in their host specificity. Erwinia outer protein 1 (Eop1) prevents Rubus-specific strains from infecting rosaceous plants outside of the Rubus genus (Asselin et al. 2011) and, thus, functions as a typical avirulence gene in Rubus strains on these nonRubus hosts (Asselin et al. 2011; Wöhner et al. 2018); Eop1 was not shown to function in virulence (Asselin et al. 2011). In contrast, the effector disease-specific protein $\mathrm{E}$ (DspE) is essential to the pathogenicity of E. amylovora (Gaudriault et al. 1997) and has variable roles in the pathogenicity of other phytopathogens (Badel et al. 2006; Bogdanove et al. 1998; Coplin et al. 2008; Guy et al. 2013; Ham et al. 2006; Jacobs et al. 2013; Kim et al. 2011). Here, we investigated the roles of Eop1 and DspE in E. tracheiphila pathogenicity and host adaptation.

Eop1 belongs to the YopJ family of T3SS effectors (T3SEs). This is a widely distributed family of T3SEs that has been divided into five major clusters (Ma and Ma 2016). Of the 18 distinct YopJ family effectors in plant pathogens, the best studied are the HopZ alleles of Pseudomonas syringae, XopJ and AvrBsT of Xanthomonas spp., and RipP2 (previously PopP2) (Peeters et al. 2013) of Ralstonia solanacearum. Eop1, which was previously called EopB and OrfB (Oh et al. 2005), is phylogenetically clustered with the $P$. syringae HopZ1 and HopZ3 effectors (Ma and Ma 2016). All YopJ family effectors share a conserved triad of amino acids that initially suggested cysteine protease activity (Orth et al. 2000) but is now known to contribute to acetyltransferase activity within eukaryotic cells (Ma and Ma 2016; Mittal et al. 2010). Although the host protein targets for acetylation generally have kinase activity in animal cells (Orth et al. 2000), they have diverse functions in plant cells, which leads to multiple pathways by which YopJ effectors influence plant pathogenesis and resistance. For example, HopZ1a suppresses pathogen-associated molecular pattern (PAMP)-triggered immunity, activates jasmonic acid signaling that suppresses salicylic acid (SA)-mediated defenses (Jiang et al. 2013), and potentially interferes with trafficking of plant defense molecules by acetylating tubulin (Cheong et al. 2014; Lee et al. 2012). Other YopJ effectors interfere with resistance by suppressing the immune response to other effectors (Lee et al. 2015; Le Roux et al. 2015; Sarris et al. 2015). Strain variation in the sequence of Eop1 in E. psidii, a close relative of E. tracheiphila, correlated with strain aggressiveness on eucalyptus (Pereira et al. 2021), suggesting that even minor variation among YopJ effectors may affect their impact on plant hosts.

DspE belongs to the widely distributed AvrE family of T3SEs. AvrE family effectors are required for the pathogenicity of some pathogens such as E. amylovora, Pantoea agglomerans pv. gypsophilae, and Pectobacterium carotovorum (Bogdanove et al. 1998; Gaudriault et al. 1997; Kim et al. 2011; Mor et al. 2001; Siamer et al. 2013), which each secrete multiple T3SEs, and Pantoea stewartii, which secretes only the DspE homolog WtsE (Ham et al. 2006). In contrast, the loss of AvrE homologs reduced but did not eliminate virulence in Pseudomonas syringae (Badel et al. 2006) and $R$. solanacearum (Jacobs et al. 2013). AvrE effectors are unusually large proteins (approximately 2,000 amino acids), possibly reflecting multiple mechanisms by which they contribute to virulence (Degrave et al. 2015), although their biochemical functions are not yet known. In addition to suppressing PAMP-triggered immunity and SA-mediated defenses, AvrE family proteins can elicit plant cell death in the absence of resistance proteins, consistent with their toxicity to yeast and cultured plant cells (DebRoy et al. 2004; Degrave et al. 2015; Yuan et al. 2020). Moreover, P. syringae AvrE contributes to effectortriggered immunity based on its role as an avirulence factor on soybean (Kobayashi et al. 1989) and as a trigger for resistance when interacting with the Arabidopsis receptor protein CAR1 (Laflamme et al. 2020).

Here, we report the first functional studies of the T3SEs of $E$. tracheiphila. We targeted Eop1 and DspE based on their importance in the host specificity and pathogenesis of the related and well-studied pathogen E. amylovora. We tested four hypotheses. First, Eop1 contributes to the inability of Et-melo strains to infect squash or to the lower aggressiveness (i.e., slower wilt) of $\mathrm{Et}$-Cl strains on muskmelon than squash, as suggested by the avirulence function of Eop1 in E. amylovora. Any evidence for the involvement of effectors in resistance, even if weak, could be a useful first step toward identifying genetic resistance to bacterial wilt of cucurbits. Second, Eop1 contributes to the virulence of the Et-melo and Et-Cl clades, consistent with the multifaceted roles in virulence of the phylogenetically related effectors HrpZ1 and HrpZ3. Third, differences in Eop1 sequence between the Et-melo and Et-Cl clades correlate with differences in aggressiveness on muskmelon, as suggested by a similar correlation among E. psidii strains on eucalyptus. And fourth, DspE is required for the pathogenicity of E. tracheiphila, in general, consistent with the critical role of DspE and WtsE in all known phytopathogens of Erwinia and Pantoea spp.

\section{RESULTS}

\section{Eop1 sequence differences correlate with E. tracheiphila clades.}

The E. tracheiphila eopl and $d s p E$ genes occur in a locus that is generally conserved among Erwinia spp. (Fig. 1). Homologs of Eop1 fall into the group III clade of the five YopJ effector clades identified by Ma and Ma (2016). A maximum-likelihood phylogenetic tree of these group III YopJ homologs shows that the E. tracheiphila Eop1 effectors are more closely related to those in some Pantoea spp. (71 to $72 \%$ identity) than to the OrfB effectors in many Erwinia spp. (57 to $59 \%$ identity) (Fig. 2). These group III YopJ family effectors fall into at least three distinct subgroups; namely, those of E. tracheiphila/ E. psidii and Pantoea spp., the other phytopathogenic Erwinia spp., and the $P$. syringae effectors, with the latter group potentially including HopZ2, the only effector previously assigned to group II (Ma and Ma 2016). Alignment of the Eop1 sequences from nine strains within Et-melo and nine strains within $E t-C 1$ indicated that Eop1 did not vary within a clade but differed between clades (Fig. 3, shown for only two strains per clade). These differences were not correlated with sequence differences among YopJ homologs in the other members of the Erwiniaceae family (Fig. 3).

\section{Deletion of eop1 did not alter the virulence of $E$. tracheiphila strains on muskmelon or squash.}

To generate deletion mutants of E. tracheiphila, we first optimized the $\lambda$ red recombineering system (LRRS) (Datsenko and Wanner 2000) for use with this pathogen. We introduced the $\lambda$ red recombinase on a stable plasmid, pKD46, to enable $\lambda$ red recombinase-mediated recombination into the chromosome; used 90-bp homologous flanking arms to generate linear fragments for the LRRS; and induced electrocompetency in E. tracheiphila cells at room temperature rather than on ice. In this manner, we 
generated unmarked $\Delta$ eopl deletion mutants (Supplementary Fig. S1) of several E. tracheiphila strains (Supplementary Table S1).

The Et-melo strains MDCuke and SCR3 both wilt muskmelon more rapidly than the Et-Cl strains BHKY and BuffGH and do not wilt squash (Supplementary Fig. S2A), and SCR3 and BHKY, as representatives of each clade, both lost all wilt activity upon loss of the T3SS (Supplementary Fig. S2B). Loss of eopl did not alter the virulence of the mutants MDCuke $\Delta$ eopl and SCR3 3 eopl on muskmelon (Supplementary Fig. S3A and B), nor did it enable them to infect squash (data not shown). Similarly, loss of eopl from the Et-Cl strain BHKY, designated BHKY $\Delta$ eopl, did not alter its virulence on either muskmelon or squash (Supplementary Fig. S3C and D). These findings indicate that $E$. tracheiphila Eop1 does not function as an avirulence factor that prevents Et-melo strains from infecting squash, or as a host-limiting factor that reduces the aggressiveness of $\mathrm{Et}-\mathrm{Cl}$ strains on muskmelon. These results also do not support a role for Eop1 in virulence, although this contribution could have been masked by other effectors, as is common for T3SEs.

\section{Overexpression of eop1 from an Et-melo strain}

in an Et-C1 strain increased virulence on muskmelon but not squash.

We constructed derivatives of MDCuke $\Delta$ eopl and BHKY$\Delta$ eopl that expressed homologous and heterologous variants of eopl and evaluated their virulence. Expression of eopl from MdCuke or BHKY in MDCuke $\Delta$ eopl did not alter virulence on muskmelon (Supplementary Fig. S4A) or enable infection of squash (data not shown). Similarly, expression of these eopl variants in BHKY did not alter virulence on squash (Supplementary Fig. S4B) but expression of eopl $1_{\mathrm{MDCuke}}$ in BHKY increased virulence on muskmelon (Fig. 4A). Expression of these eop1 variants in BHKY in planta was confirmed using RNA isolated from the xylem sap of infected muskmelon plants (Fig. 4B). These findings demonstrate that the Eop1 variants in the two E. tracheiphila clades have distinct functions, with the Eop1 variant from the Et-melo strain increasing the virulence, or aggressiveness, of an Et-Cl strain on muskmelon. Although BHKY $\Delta$ eopl $\left(\mathrm{pN}\right.$-eopl $\left.1_{\mathrm{MDCuke}}\right)$ was more virulent than the wildtype BHKY (Fig. 4A), it remained less virulent than the Et-melo strains on muskmelon (Supplementary Figs. S2 to S4), indicating that eopl $1_{\text {MDCuke }}$ contributed to but was not sufficient for rapid wilt of muskmelon.

\section{DspE contributes to the virulence of Et-melo strains but} is required for the pathogenicity of an Et-C1 strain.

Similar to Eop1, the DspE effectors exhibit sequence differences between the two E. tracheiphila clades but not within the clades (Supplementary Fig. S5). Loss of DspE and its cognate chaperone DspF reduced the virulence of Et-melo strains MDCuke and SCR3 on muskmelon and cucumber, although these mutants retained the ability to induce wilt (Fig. 5). The large reduction in virulence suggests a central role for DspE in the virulence of Et-melo strains, while the remaining virulence demonstrates that DspE is not absolutely required for the pathogenicity of this clade. Loss of $d s p E F$ did not enable MDCuke or SCR3 to wilt squash (Supplementary Fig. S6), indicating that DspE does not have a role in avirulence. In contrast, loss of $d s p E F$ completely eliminated the ability of Et-Cl strain BHKY to cause disease on squash, muskmelon, and cucumber (Fig. 6).

These collective results highlight distinct roles for DspE in the two E. tracheiphila clades. Specifically, DspE is a major factor contributing to but is not required for virulence of the Et-melo clade, whereas it is absolutely required for the pathogenicity of the $E t-C l$ clade. Prior studies have found that DspE is required for the pathogenicity of all Erwiniaceae family pathogens examined; thus, the Et-melo clade strains are exceptional within this family (Fig. 7). Among a taxonomically broader array of pathogens, only the Pectobacterium genus includes strains that differ in their requirement for DspE for pathogenicity. Differences in the impact of DspE loss likely reflect the presence of one or more additional effectors with compensatory functions in the strains exhibiting residual virulence.

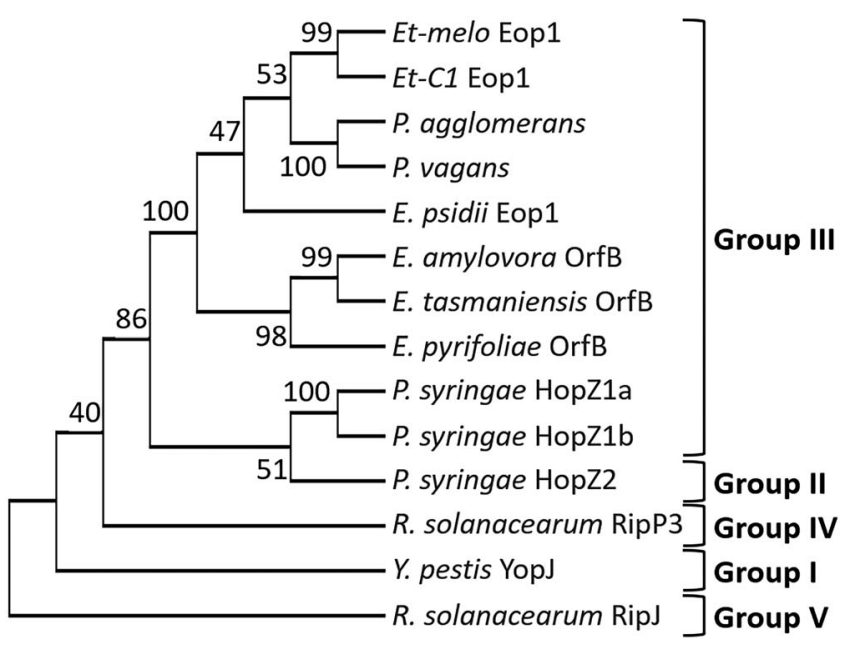

Fig. 2. Phylogenetic relatedness of YopJ effectors within the group III clade, with representatives from other YopJ family groups for comparison. Protein sequences were aligned using MUSCLE (Edgar 2004) and the phylogenetic tree was produced using MEGA X (Kumar et al. 2018) using a maximumlikelihood approach and bootstrapping with 1,000 replicates to generate the consensus trees shown. Protein sequences for the effectors representing groups I, II, IV, and V, along with the HopZ1a and HopZ1b effectors of Pseudomonas syringae, are from Ma and Ma (2016), with RipP3 (Peeters et al. 2013) referring to PopP3 (Ma and Ma 2016). The GenBank accession numbers for the remaining YopJ family effectors were Et-melo Eop1 (Erwinia tracheiphila MDCuke, AXF77196.1) Et-C1 Eop1 (E. tracheiphila BuffGH, WP_016191031.1), Pantoea agglomerans (WP_158150056.1), P. vagans (WP_061060943.1), E. psidii Eop1 (WP_124231866.1), E. amylovora OrfB (AAF63400), E. tasmaniensis OrfB (WP_012440293.1), and E. pyrifoliae OrfB (WP_012669297.1).

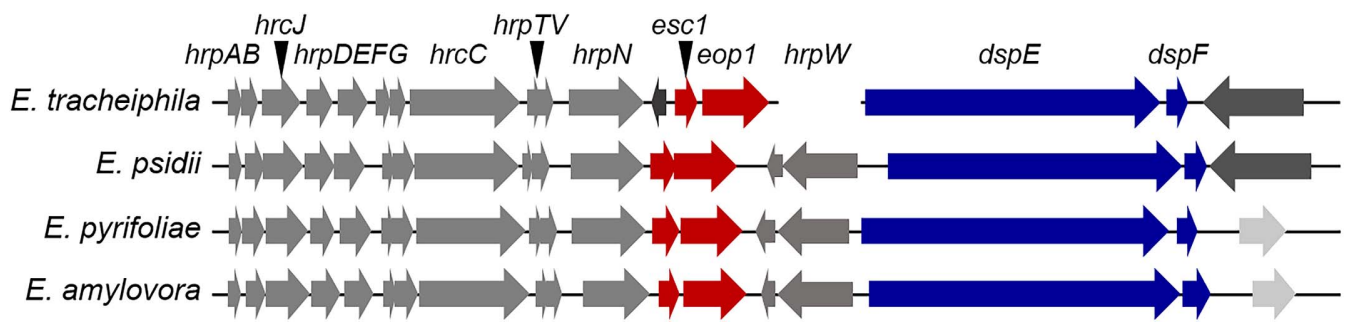

Fig. 1. Genetic organization of the eopl-dspE locus of several Erwinia spp. 
The chaperone DspF is required for virulence of Et-melo strains.

Whereas DspE was required for the virulence of E. amylovora (Triplett et al. 2008) and Pantoea stewartii subsp. stewartii
(Ham et al. 2006), loss of the cognate chaperone DspF in these pathogens reduced but did not eliminate their virulence. These results indicate that $\mathrm{DspF}$ contributes to but is not absolutely required for stability and secretion of DspE in these pathogens.
E. amylovora

E. pyrifoliae

E. psidii

Et-melo SCR3

Et-melo MDCuke

$E t-C 1$ BuffGH

$E t-C 1$ BHKY

E. amylovora

E. pyrifoliae

E. psidii

Et-melo SCR3

Et-melo MDCuke

$E t-C 1$ BuffGH

Et-C1 BHKY

E. amylovora

E. pyrifoliae

E. psidii

Et-melo SCR3

Et-melo MDCuke

Et-Cl BuffGH

Et-C1 BHKY

E. amylovora

E. pyrifoliae

E. psidii

Et-melo SCR3

Et-melo MDCuke

$E t-C 1$ BuffGH

$E t-C 1$ BHKY

E. amylovora

E. pyrifoliae

E. psidii

Et-melo SCR3

Et-melo MDCuke

$E t-C 1$ BuffGH

Et-Cl BHKY
MNISGLRGGYKSOAQQADNASSSS----TQGSPAPTGR--RLQRODA-I PANYRYHASOMPATPERARVAARYASOASSS------- 73 MNVSGLRAGQRSPSQQADHAPSSS----TQASPAQTGR--RLQRQDA-LPANNRYHASQTPATPDRARAAARYASGASSSAAPAAGP 80 MNVFGIKIGHRNPSQQTERTPSP----SPQASPLPAGRAGRLQRQNA-LSPTIRYNARSTPSTPDRARASSMHGGAGSSSPACSSGA 82 MNVFGYRIGRKSSSQQEEQTPSSSPLASPQSSPLPAGRAGRLQRQNATLSNNTRYNARSTPGTPDRARATSRHSGEGSSSSAYSTGP 87 MNVFGVRIGRKSSSQQEEQTPSSSPLASPQSSPLPAGRAGRLQRQNATLSNNTRYNARSTPGT PDRARATSRHSGEGSSSSAYSTGP 87 MNVFGV IIGRKSSSOOEEQTPSSSPLASPQSSPLPAGRAGRLQRONATLSNNTRYNARSTPGTPDRARATSRHSGEGSSSSAYSTGP 87 MNVFGY IIGRKSSSQQEEQT PSSSPLASPQSSPLPAGRAGRLQRQNATLSNNTRYNARSTPGTPDRARATSRHSGEGSSSSAYSTGP 87

AGPSIL-LSRQSGHRENPSLVRFHETMQQSPKMSRGDPLPEKPEIVPKRLQEKIDSVNLPRLNKLDKNLYEYGKMATELAKEGSGSS 159 AGPSMA-LSRQHANRENPTFARFHDAMQQSPKMLRASPVPEKPEKIPERLQQKADAIDLPGLKKLDKSLYEYAKLATELVKEGAGPD 166 ASPSRG-LTRQAGRRENAQLAQFHDTMRASPKMSRNDPIPETPPETPKRLQQKMDAIDLPKLKSLDKDLYHYAPMATELVNENNGSN 168 ASSSRAVLVRQGGNREHSQLAQFHEMMQVSPKISRNDPLPETPES IPRRLQEKMDTVNLPELEKLDGGLYEYAKMAIERVNEKKGAD 174 ASSSRAVLVRQGGNREHSQLAQFHEMMQVSPKISRNDPLPETPESIPRRLQEKMDTVNLPELEKLDGGLYEYAKMAIERVNEKKGAD 174 ASSSRAVLVRQGGNREHSQLAQFHEMMQVSPKISRNDPLPETPESIPRRLQEKMDTVNLPELEKLDGGLYEYAKMAIERVNEKKGAD 174 ASSSRAVLVRQGGNREHSQLAQFHEMMQVS PKISRNDPLPETPESIPRRLQEKMDTVNLPELEKLDGGLYEYAKMAIERVNEKKGAD 174

VALMRMDKKVLPLLADAENARNPGLNLHVYKRGEECYQAIKEQHKIVQQSGQPKTMRALYPPFIGMPDHHIALDIHLRPGHRPSIVG 246 NDLADMDRKLLPLLADAENARNPGLNLRTFKSSEECYRAIKDONKSVOOSROPMSMRVLYPPLKGARDHRVALDIOFRPGHRPSIVG 253 AVLMRMDKKMLPLIAEAENARHPGLNLHVFKNADECYKAIKMQNKQVWSSKQPMNMRVLYSPIKGMPDHHVALDVQFRPGHRPSVMC 255 KQLSELDKKMLPLFAEAENARHPDLNLHVFRGPEACYKAIKEQNKKAWDSRQPMNMRVVFSPSRGI PDHHVALDVQLRPGHHPSVVC 261 KQLSELDKKMLPLFAEAENARHPDLNLHVFRGPEACYKAIKEQNKKAWDSRQPMNMRVVFSPSRGI PDHHVALDVQLRPGHHPSVVC 261 KQLSELDKKMLPLFAEAENARHPDLNLHVFRGPEACYKAIKEQNKKAWDSRQPMNMRVVFSPSRGI PDHHVALDVQLRPGHHPSVVC 261 KOLSELDKKMLPLFAEAENARHPDLNLHVFRGPEACYKAIKEQNKKAWDSROPMNMRVVFSPSRGI PDHHVALDVQLRPGHHPSVVC 261

FESALGHMVDPIRQGIAQGLRGAKVHMVGNRIQNSEWDCIMYSLNNALKSFKHHDEYTARLHKGE--K-IPVPAEFFKHAQSKSMVE 330 FESAPGNLAELLQHELEHALRGAKVQVVENTIQNSLRGCSMFALNNALKSFKHHDEYTARLHSGE--KQVPVPAEFLKHAHSKALVE 338 MESALGHMMDT IQMGIEHGLKGAKVKMVGNTIQASQWDCAMYALNNALKLFKHHDEYTARVHGGE--TDVSLPAEFLKHAQSRSHIR 340 FESALWGMMNE IR GIEHGLKESKVKLIGNFVQASDWDCAMFALSNALKLYKHHDEYTSRLHAGE-DNVRIPSA LIKHAQSKGHAE 346 FESALWGMMNEIR G IEHGLKESKVKLIGNFVQASDWDCAMFALSNALKLYKHHDEYTSRLHAGE--ENVRIPSE LIKHAQSKGHAE 346 FESALWGMMNE IROD IEHGLKESKVKLIGNFVQASDWDCAMFALSNALKLYKHHDEYTSRLHAGE EE ENVRIPSEFIKHAQSKGHAE 348 FESALWGMMNE IR D IEHGLKESKVKLIGNFVQASDWDCAMFALSNALKLYKHHDEYTSRLHAGE EE ENVRIPSE FIKHAQSKGHAE 348

GLPHQDAIVTKDKGGLHAETLLHRNLAYRADRFDHACNTS IEGFRMQEIQRAGEFLSAQNRKS 393 GHRHQDAIVSKDKGGLHAETLLHRNLAYRADRINHSYSTS IEGFRLQEIQRAGEFLAARKQRR 401 ESPNKNDIVSKDKGGLHAETLMHRNLAYRTQRFEKAYSTSIEGFRFQEIQRAGDYLAAQRGLK 403 RQGRRNDIVTKDKGGLHAETLLHRNLAYRAQRFDKAYSTS IEGFRFQEIQRAGDYLAAQRGRK 409 RQGRRNDIVTKDKGGLHAETLLHRNLAYRAQRFDKAYSTSIEGFRFOEIORAGDYLAAQRGRK 409 RQGRRNDIVTKDKGGLHAETLLHRNLAYRAQRFDKAYSTSIEGFRFQEIQRAGDYLAAQRGRK 411 RQGRRNDIVTKDKGGLHAETLLHRNLAYRAQRFDKAYSTS IEGFRFQEIQRAGDYLAAQRGRK 411

Fig. 3. Eop1 exhibits clade-specific sequence differences among Erwinia tracheiphila strains. Eop1 sequences of Et-C1 and Et-melo strains exhibit three single-amino acid differences and one two-amino acid-insertion-deletion. Amino acid sequences were aligned using Clustal Omega (Madeira et al. 2019). The GenBank accession numbers for the proteins shown are Et-melo (AXF77196.1) Et-C1 (WP_016191031.1), E. psidii (WP_124231866.1), E. amylovora (AAF63400), and E. pyrifoliae (WP_012669297.1). Eop1 sequences for additional E. tracheiphila strains are from Liu (2015).
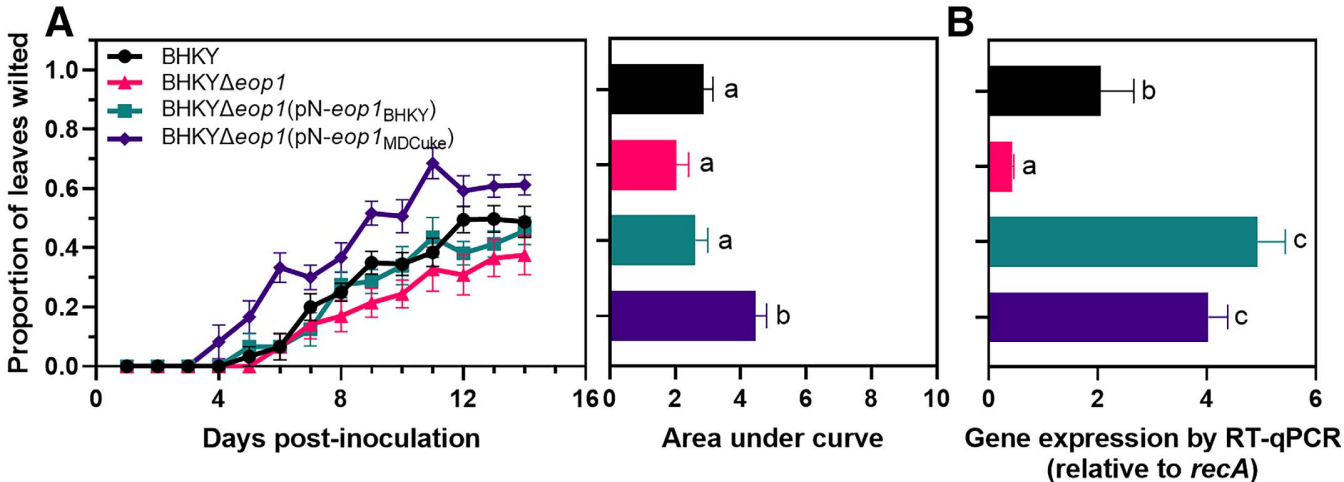

Fig. 4. Expression of eopl from Et-melo in Et-C1 increased virulence on muskmelon. A, Proportion of leaves wilted per plant (left panel) and area under disease progress curve (right panel) of the wild-type Et-Cl strain BHKY, BHKY $\Delta$ eopl, and BHKY $\Delta$ eopl expressing homologous (eopl $\left.1_{\mathrm{BHKY}}\right)_{\text {and }}$ heterologous (eopl $1_{\text {MDCuke }}$ ) variants of eopl on muskmelon. The experiment was repeated four times with 5 to 10 replicates each; the results of one representative experiment are shown. B, In planta expression of eopl in the indicated cells was measured using real-time quantitative reverse-transcription PCR (RT-qPCR) and relative expression was calculated from the cycle threshold $\left(\mathrm{C}_{\mathrm{T}}\right)$ values using expression of the recA gene for normalization; results are shown as $2^{-\Delta \Delta \mathrm{Ct}}$ values. The experiment was repeated twice with three technical replicates. Strains are indicated by the same color in all figures. Values shown are mean \pm standard error of the mean, and were analyzed by analysis of variance $(\mathrm{A}, P=0.0002$; $\mathrm{B}, P=0.03)$ followed by a Tukey's multiple comparison test. 
In contrast, the loss of $d s p F$ reduced the virulence of SCR3 and MDCuke to a similar extent as the loss of $d s p E$ or $d s p E F$ (Fig. 8), suggesting that DspF is required for DspE secretion in the E. tracheiphila strains.

A Muskmelon host
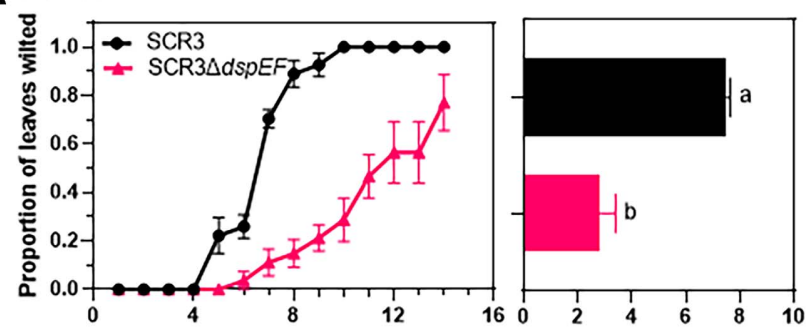

B Muskmelon host
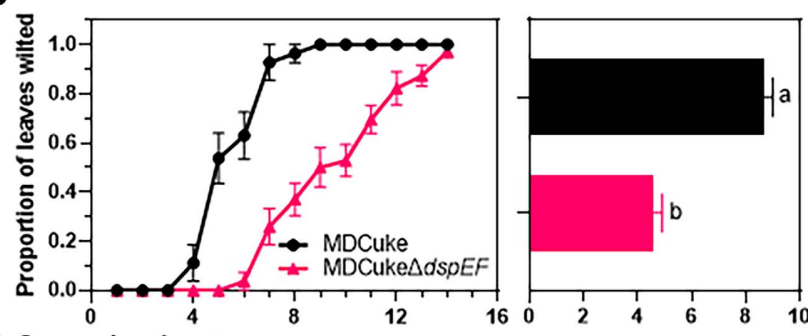

C Cucumber host

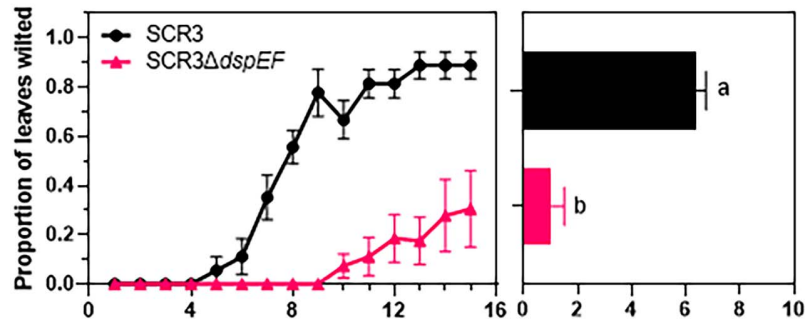

D Cucumber host
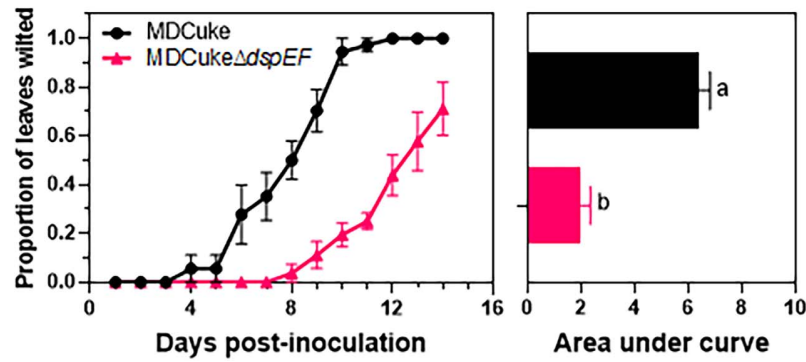

Fig. 5. Effector DspE contributes to the virulence of the Et-melo strains on $\mathbf{A}$ and $\mathbf{B}$, muskmelon and $\mathbf{C}$ and $\mathbf{D}$, cucumber. Plants were infected with wild-type strains and $\triangle d s p E F$ mutants of SCR3 (A and C) and MDCuke (B and D). Comparisons were performed using Student's $t$ tests $(P<0.0001)$.

\section{DISCUSSION}

This report presents the first study to explore the genetic basis of pathogenicity and host adaptation of E. tracheiphila and the contribution of individual E. tracheiphila T3SEs to virulence. Most gram-negative phytopathogens exploit T3SEs as part of a coevolutionary arms race in which the T3SEs influence pathogen virulence and plant recognition of the pathogen (Bastedo et al. 2020; Schreiber et al. 2021). Although the T3SS enables the introduction of T3SEs into living host cells, the conductive elements colonized by xylem pathogens are composed of dead cells. The T3SS of xylem pathogens that can invade nonvascular tissues may enable protein translocation into living cortical and mesophyll cells whereas, in the xylem, the T3SS may enable protein translocation at the pit membrane into the living parenchyma cells that surround the xylem vessels (Hilaire et al. 2001; Morris et al. 2018). E. tracheiphila has an unusual mix of traits among xylem pathogens, making it challenging to predict the role of the T3SEs. It is a xylem-restricted, obligately vectortransmitted pathogen that has a T3SS. Thus, it is distinct from $R$. solanacearum and Xanthomonas campestris pv. campestris, which are not xylem restricted; from $X$. oryzae pv. oryzae and $X$. translucens pv. translucens, which are xylem restricted but not vector transmitted; from Xylella fastidiosa, Xanthomonas albilineans, and gram-positive xylem pathogens, which all lack a T3SS; and from the closely related pathogens $P$. stewartii subsp. stewartii and E. amylovora, which cause wilt but are not

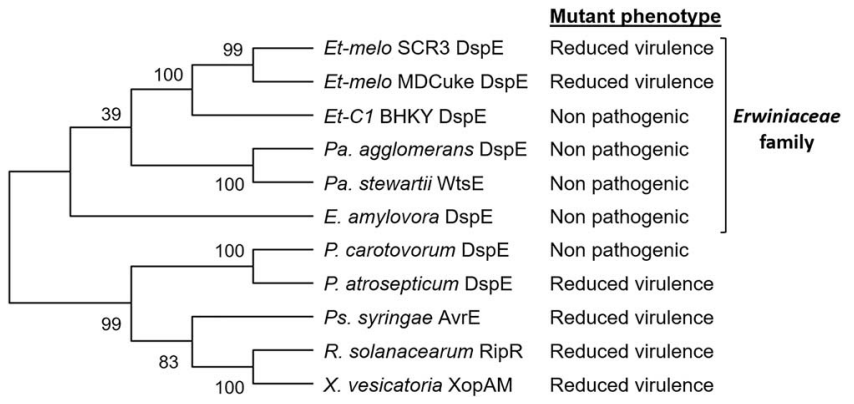

Fig. 7. Phylogeny of the AvrE effector family and their contributions to virulence. A maximum-likelihood tree of the AvrE sequences was generated. The DspE sequences of Erwinia tracheiphila strains SCR3 and BHKY (Supplementary Fig. S5) were obtained from their complete genome sequences, which we generated using the PacBio platform (unpublished data). GenBank accession numbers for the AvrE family effector proteins were: E. tracheiphila strain MDCuke DspE (AXF77194.1), Pantoea agglomerans pv. gypsophilae DspE (AAF76343.1), P. stewartii subsp. stewartii WtsE (AAG01467.2), E. amylovora DspE (CCO81193.1), Pectobacterium carotovorum DspE (CBI45053.1), P. atrosepticum DspE (WP_039292044.1), Pseudomonas syringae pv. tomato strain DC3000 DspE (AAF71499.1), Ralstonia solanacearum RipR (previously PopA) (WP_003262779.1), and Xanthomonas vesicatoria XopAM (EGD07146.1).
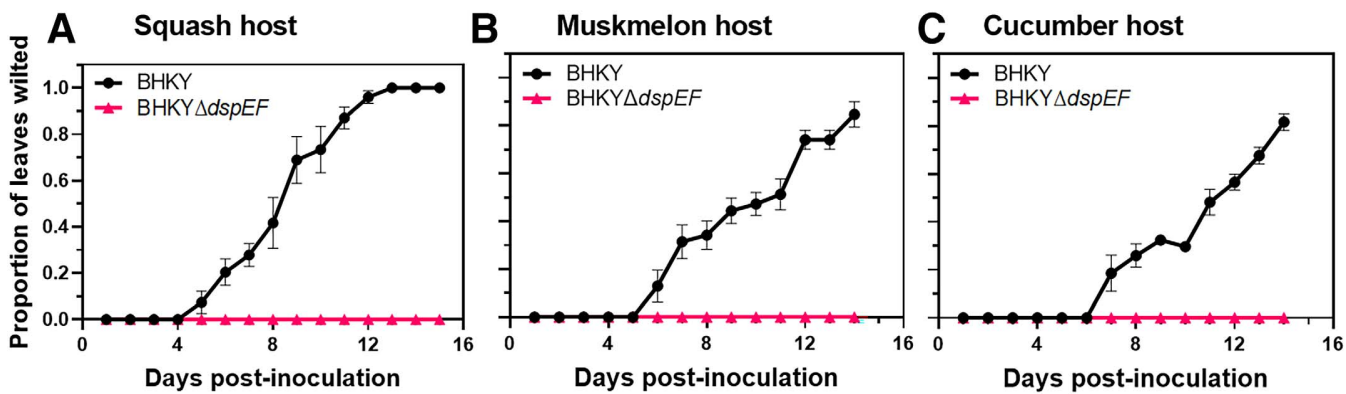

Fig. 6. Effector DspE and its chaperone DspF are required for pathogenicity of the $E t-C l$ strain BHKY on A, squash, B, muskmelon and C, cucumber. A BHKY $\Delta d s p E$ mutant was similar to BHKY $\Delta d s p E F$ in its inability to wilt squash and muskmelon (data not shown); it was not examined on cucumber. 
xylem restricted or obligately vectored (Bae et al. 2015; Eigenbrode et al. 2018; Yadeta and Thomma 2013). We used knowledge of the T3SEs in E. amylovora and $P$. stewartii subsp. stewartii to guide our studies based on both the phylogenetic relatedness of these pathogens to E. tracheiphila and the prior body of literature on the role of their T3SEs in host adaptation and virulence.

E. tracheiphila strains fall into phylogenetic clades that differ in their virulence patterns across cucurbit species (Nazareno and Dumenyo 2015; Rojas et al. 2013; Shapiro et al. 2018). We identified Eop1 as a candidate T3SE contributing to the host specificity of the Et-melo clade based on its role as a hostlimiting factor in E. amylovora strains (Asselin et al. 2011). Here, we found that loss of Eop1 did not enable Et-melo clade strains to infect squash; thus, Eop1 did not have a detectable avirulence function in the Et-melo strains. This finding could reflect the absence of resistance genes in the squash cultivar

A Muskmelon host
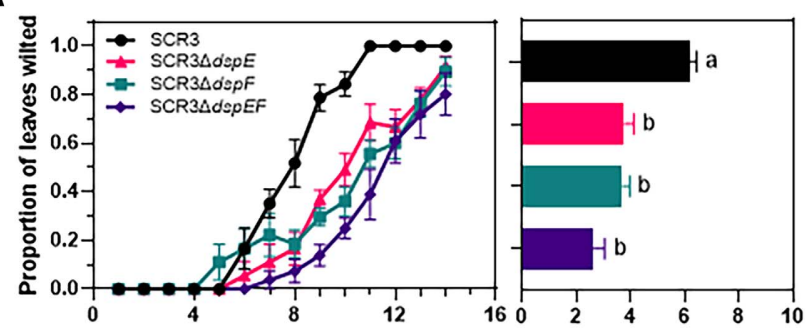

B Muskmelon host
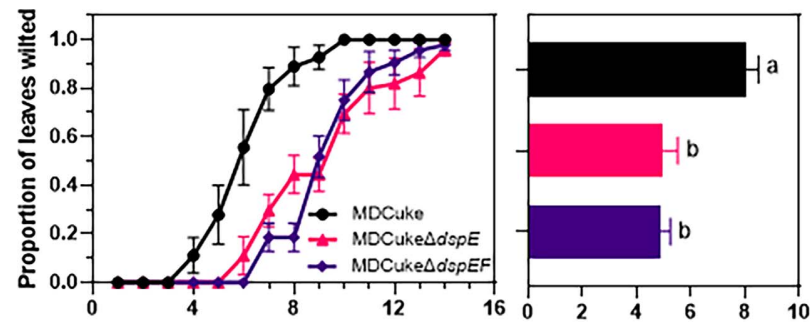

C Cucumber host
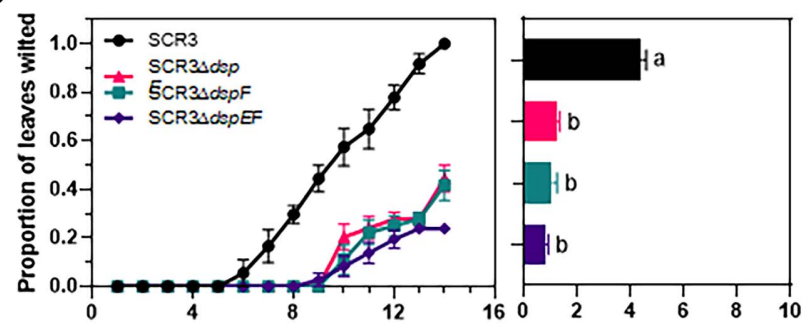

D Cucumber host
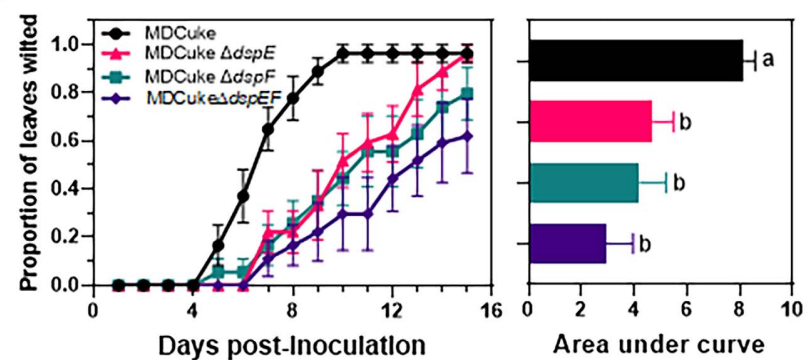

Fig. 8. The chaperone DspF is required for the virulence function of DspE in the Et-melo strains MDCuke and SCR3 on A and B, muskmelon and $\mathbf{C}$ and $\mathbf{D}$, cucumber. Plants were infected with infected with wild-type strains and $\triangle d s p E F$ mutants of SCR3 (A and C) and MDCuke (B and D). Comparisons were performed using one-way analysis of variance and a Tukey's multiple comparison test (A, $P<0.0001 ; \mathrm{B}, P<$ $0.0001 ; \mathrm{C}, P=0.001$; and $\mathrm{D}, P<0.0001)$. used, although we cannot discount that resistance resulted from an alternative T3SE. Our results are consistent with the absence of known genetic resistance to bacterial wilt in cucurbits.

Strains of the E. tracheiphila clade Et-Cl exhibit a host preference indicated by their more rapid induction of wilt and, thus, greater aggressiveness on squash than on muskmelon. This type of host preference has been seen with other phytopathogens such as the cucurbit pathogen Acidovorax avenae subsp. citrulli, for which strains have similarly been divided into groups based on differential aggressiveness on distinct cucurbit genera (Eckshtain-Levi et al. 2014; Walcott et al. 2004). Loss of eopl did not influence the virulence of the Et-melo or Et-C1 clade strains on any host, as is common in pathogens with many T3SEs due to the dispensability of individual T3SEs. In contrast, overexpression of eopl increased the virulence of an Et-Cl strain on muskmelon, demonstrating a role for Eop1 in virulence. Interestingly, this contribution was specific to the Eop1 variant present in the Et-melo clade, because Eop1 from Et-melo but not from Et-Cl increased the virulence of an Et-ClDeopl mutant. The eopl gene sequence was invariable within each clade, and the eopl gene from each clade was cloned into the same vector and expressed by the same overexpression promoter. The clade-specific Eop1 variants exhibited only four sequence polymorphisms, three single-amino-acid differences, and one two-amino-acid insertiondeletion, but none were in regions of known function. This result is concordant with a correlation among differences in Eop1 sequence and E. psidii aggressiveness on eucalyptus (Pereira et al. 2021), and suggests that minor sequence variations within YopJ-family effectors affect their impact on plant hosts. Collectively, our data demonstrate that Eop1 has distinct roles in the virulence of each clade on muskmelon, supporting the possibility that Eop1 is one factor contributing to adaptation of E. tracheiphila to this host.

We also demonstrated that the role of DspE in E. tracheiphila virulence differed in the two E. tracheiphila clades. A large reduction in Et-melo virulence upon the loss of DspE supports a central role for DspE in virulence; however, its residual virulence activity indicates that DspE is not absolutely required for the pathogenicity of the Et-melo clade, unlike the Et-Cl clade and in all previous Erwiniaceae family phytopathogens examined. The Et-melo clade strains may have one or more other effectors that compensate for the loss of DspE, similar to a Pseudomonas syringae pv. tomato strain in which AvrE is functionally redundant with HopM1 (Badel et al. 2006; Xin et al. 2016), although E. tracheiphila strains lack an HopM1 homolog. The loss of DspE did not enable two Et-melo strains to wilt squash, which is consistent with the lack of evidence for a role for DspE homologs in effector-triggered immunity in E. amylovora and Pantoea stewartii subsp. stewartii. The difference in the requirement for DspE for virulence between the two E. tracheiphila clades identifies this as the only phytopathogenic species that includes both strains that do and strains that do not require an AvrE family member for disease induction. To date, a similar diversity of DspE functions has been detected only at the species level, namely, in Pectobacterium carotovorum and $P$. atrosepticum strains. Our data showing distinct roles of DspE in the Et-melo and Et-Cl clades are consistent with the distinct T3SE repertoires in these clades, as highlighted in E. tracheiphila genomic sequence data (Shapiro et al. 2018).

Like many T3SEs (Ham et al. 2006), most T3SEs in the AvrE family are coexpressed with a chaperone that is required for efficient folding, stability, secretion, and translocation of the effector into host cells (Gaudriault et al. 2002). Studies with E. amylovora and Pantoea stewartii subsp. stewartii found that loss of DspE eliminated pathogenicity but loss of the coexpressed chaperone DspF did not (Ham et al. 2006; Triplett et al. 2008). More recently, three chaperones were shown to 
contribute additively to the secretion and translocation of DspE in E. amylovora (Castiblanco et al. 2018); these three chaperones include DspF, the Eop1 chaperone Esc1, and a chaperone to the T3SE Eop4. We found that two Et-melo strains exhibited a similar loss in virulence upon loss of DspF or DspE, indicating that DspF is sufficient for the secretion of DspE. Thus, even though these Et-melo strains encode an Esc1 chaperone, this chaperone did not measurably compensate for the loss of DspF as in E. amylovora (Castiblanco et al. 2018).

Due to the lack of known genetic resistance to bacterial wilt of cucurbits, this disease is managed in conventional agriculture primarily by insecticides that kill the cucumber beetle vectors (Rojas et al. 2015). Although Eop1 was shown to induce resistance in apple cultivars against the fire blight pathogen E. amylovora, we did not find evidence that Eop1-triggered immunity was involved in host specificity or host preference in the E. tracheiphila clades examined. Thus, these studies do not provide a foundation to support further search for such resistance. However, these studies have illustrated differences in the portfolio of effectors influencing the virulence of the two clades, with differences in both the function of homologous effectors and the functional redundancy within their effector repertoires. Knowledge of the molecular drivers of virulence in E. tracheiphila and their diversification among E. tracheiphila strains may help in identifying future management alternatives for bacterial wilt of cucurbits.

\section{MATERIALS AND METHODS}

\section{Bacterial strains, growth conditions, and inoculum preparation.}

The bacterial strains and plasmids for this study are described in Supplementary Table S1. E. tracheiphila strains were grown in King's B (KB) medium (King et al. 1954) at $28^{\circ} \mathrm{C}$, unless otherwise described. Escherichia coli strains were grown in Luria-Bertani medium at $37^{\circ} \mathrm{C}$. The following antibiotics were added, when needed, at $50 \mu \mathrm{g} / \mathrm{ml}$ : rifampin (Rif), kanamycin $(\mathrm{Km})$, spectinomycin, and ampicillin (Amp). To prepare cells for plant inoculation assays, Erwinia tracheiphila strains were recovered from cryogenically preserved glycerol stocks $\left(-70^{\circ} \mathrm{C}\right)$ on KB agar amended with Rif. The cells were incubated for 3 to 4 days, after which a single colony was transferred to a fresh plate to make a lawn. Cells from a 2-day-old lawn were suspended in $10 \mathrm{mM}$ phosphate buffer (PB) and normalized to an optical density at $600 \mathrm{~nm}\left(\mathrm{OD}_{600}\right)$ of 0.5 (approximately $\left.2.5 \times 10^{8} \mathrm{CFU} / \mathrm{ml}\right)$. A nonionic organosilicone surfactant (Silwet L-77) was added to each bacterial suspension at $0.02 \%$ ( $\mathrm{vol} / \mathrm{vol})$.

\section{Construction of deletion mutants and complementation constructs.}

Deletion mutants were generated using the $\lambda$ red recombinase system, which comprises recombinase components expressed under the control of an arabinose-inducible promoter on the plasmid pKD46 (Datsenko and Wanner 2000). PCR products were generated using primers (Supplementary Table S2) that target sequences that were conserved across the Et-melo and Et-Cl clades. The PCR products used to generate the $d s p E F$ mutants included $1-\mathrm{kb}$ regions flanking $d s p E F$ in the genomes, whereas the PCR products used to generate the eopl, $d s p E$, and $d s p F$ mutants included 90-nucleotide (nt) regions flanking these genes in the genomes. The PCR products also contained a kanamycin cassette (kan) flanked by flippase recognition target (FRT) sites, generating chimeric PCR products that were subsequently introduced via electroporation into E. tracheiphila cells.

More specifically, the linear fragments used to generate the $\triangle d s p E F$ mutants were constructed by using splice-overlapextension PCR (Ho et al. 1989). PCR products containing the 1-kb regions upstream and downstream of $d s p E F$ were ligated to a FRT-kan-FRT cassette that was generated by PCR using pKD13 (Datsenko and Wanner 2000) as a template. The resulting fragment was cloned into pTOK2T (Chen et al. 2010). This plasmid was used as a template to generate a chimeric linear fragment, which was electroporated into cells of E. tracheiphila strains that had been transformed with pKD46 (Datsenko and Wanner 2000). The linear fragments used to generate the $\Delta e o p 1, \Delta d s p E$, and $\Delta d s p F$ mutants contained the FRT-kan-FRT cassette that was amplified from plasmid pKD13 using primers that incorporated into the final product 90 -bp sequences homologous to the regions immediately flanking the target genes in the genomes (Supplementary Table S2).

To generate mutants, E. tracheiphila cells containing pKD46 were grown at $28^{\circ} \mathrm{C}$ for 2 to 3 days in $\mathrm{KB}$ broth amended with Amp. When cells reached an $\mathrm{OD}_{600}$ of 0.3 , freshly made $\mathrm{L}$-arabinose was added to a final concentration of $10 \mathrm{mM}$ to induce expression of the $\lambda$ phage red recombinase genes. Cells were harvested at an $\mathrm{OD}_{600}$ of 0.5 and washed three times with roomtemperature, sterile distilled water. The room-temperature wash was adopted because E. tracheiphila competency appeared to be reduced by washing in cold sterile water. After the washes, the cells were suspended in sterile distilled water and placed on ice for 15 to $20 \mathrm{~min}$ immediately prior to electroporation. The linear chimeric fragments that contained the flanked kan cassette were introduced into a high-density suspension $\left(10^{10} \mathrm{CFU} / \mathrm{ml}\right)$ of ice-cold electrocompetent cells at a concentration of $>5 \mu \mathrm{g}$ per $100 \mu \mathrm{l}$ of cells in a $0.2-\mathrm{cm}$ cuvette using a gene pulser electroporator (Bio-Rad, Hercules, CA, U.S.A.). The high DNA density was achieved by pooling and concentrating products generated by multiple PCR reactions. Electroporated cells were transferred to $1 \mathrm{ml}$ of ice-cold KB broth and incubated for 6 to $10 \mathrm{~h}$, then plated on $\mathrm{KB}$ agar supplemented with Km. Mutants were confirmed by PCR using primers shown in Supplementary Table S2, and the kan cassette was removed by introduction of pFlp $2 \Omega$ (Wu et al. 2013).

To evaluate complementation of the $\Delta$ eopl mutants, PCR fragments containing the eopl genes from MDCuke and BHKY were cloned into the EcoRV site of pN (Chen et al. 2010). These fragments included the regions upstream of the translation start sites to capture their native promoters; specifically, they included the complete 109-nt intergenic region along with $138 \mathrm{nt}$ (MDCuke) or $131 \mathrm{nt}$ (BHKY) of $3^{\prime}$ terminus of the upstream gene. Plasmid $\mathrm{pN}$ is a derivative of the broad-host-range vector pME6041 (Heeb et al. 2000) that has a 733-bp nptII promoter inserted upstream of the multiple cloning site. The resulting constructs, $\mathrm{pN}$-eopl $1_{\mathrm{MDCuke}}$ and $\mathrm{pN}$-eopl $1_{\mathrm{BHKY}}$, contained eopl under the control of the native promoter fused in tandem with the nptII promoter. These plasmids were introduced into the $\mathrm{MDCu}-$ ke $\Delta$ eopl and BHKY $\Delta$ eopl mutants by electroporation.

\section{Plant growth conditions.}

The cucurbit cultivars used in this study included muskmelon (Cucumis melo 'Athena'), zucchini squash (Cucurbita pepo 'Partenon F1'), and cucumber (Cucumis sativus 'Marketmore') (organically grown seed from Johnny's Selected Seeds, Winslow, ME, U.S.A.). Seeds were sown in $10-\mathrm{cm}$ pots containing a matrix of peat moss, coarse perlite, and Metro-Mix 300 (Sun Gro Horticulture, Canada Ltd., Vancouver, BC, Canada). Seedlings were maintained in a growth chamber (Percival Scientific Inc.) at $28^{\circ} \mathrm{C}$ under a photoperiod of $12 \mathrm{~h}$ of light and $12 \mathrm{~h}$ of darkness and $70 \%$ relative humidity. Plants were watered every other day and fertilized with 15-5-15 NPK (Peters Excel; ICL Specialty Fertilizers) 2 days before inoculation.

\section{Inoculation and disease assessment.}

Plants were inoculated with E. tracheiphila when they were 2 weeks old. The site closest to the petiole of the adaxial surface 
of the youngest fully expanded leaf was punctured with a florist's pin frog, as described previously (Liu et al. 2018), and $200 \mu \mathrm{l}$ of cell suspension (approximately $2.5 \times 10^{8} \mathrm{CFU} / \mathrm{ml}$ ) was applied to the punctured site. For negative controls, plants were inoculated with $\mathrm{PB}$ in the same manner. Inoculated plants were incubated as described for the seedlings and rated daily for wilt development based on the total number of leaves and the number of leaves wilted per inoculated plant. Once plants reached $100 \%$ wilt, newly emerging leaves were not counted and the plants were not monitored further. Data were collected daily for at least 2 weeks.

\section{Evaluation of gene expression in cells recovered from the xylem.}

To evaluate eopl expression in bacteria during growth in planta, 2-week-old seedlings of muskmelon were inoculated with BHKY, BHKY $\Delta e o p 1$, BHKY $\Delta e o p l\left(\mathrm{pN}\right.$-eop $\left.1_{\mathrm{MDCuke}}\right)$, and BHKY $\Delta$ eopl(pN-eopl $\left.1_{\mathrm{BHKY}}\right)$. At the first appearance of wilt symptoms, xylem sap was collected from infected plants following surface sterilization of an excised segment with $70 \%$ ethanol. The xylem sap was collected by manually squeezing the aerial portion of the cut stem and collecting the sap with a pipette. Immediately following xylem sap collection, the sap was combined with RNAprotect Cell Reagent (Qiagen) for $10 \mathrm{~min}$ at room temperature to preserve RNA integrity. The cells in this mixture were collected by centrifugation and the pellets were either used immediately for RNA extraction or frozen at $-70^{\circ} \mathrm{C}$ for RNA extraction at a later time. RNA was extracted using an RNeasy Mini Kit (Qiagen) and the DNA was removed using an on-column DNase I digestion (Qiagen).

The eopl transcripts were measured using real-time quantitative reverse-transcription PCR (RT-qPCR) with the qScript OneStep SYBR Green RT-qPCR kit (Quantabio, Beverly, MA, U.S.A.). Relative expression was calculated from the cycle threshold $\left(\mathrm{C}_{\mathrm{T}}\right)$ values, using expression of the recA gene for normalization. The primers $5^{\prime}$-GGGGTATGATGAATGAGATTC GGC-3' and 5'-ATTTCAGCGCATTACTCAGCGC-3' were used to evaluate expression of eopl, and 5'-CCATATCTA CGGGTTCTCTCTCGC-3' and 5'-AGCGATAACCTGCAAA GTCAGC $-3^{\prime}$ were used to evaluate expression of recA. In all, $100 \mu \mathrm{g}$ of total RNA was used for each of three technical replicates, each in a total reaction of $25 \mu \mathrm{l}$. RT-qPCR was performed using the Mastercycler ep realplex thermocycler (Eppendorf) under the following conditions: 1 cycle at $95^{\circ} \mathrm{C}$ for $2.5 \mathrm{~min}, 40$ cycles at $95^{\circ} \mathrm{C}$ for $15 \mathrm{~s}$, and 1 cycle at $60^{\circ} \mathrm{C}$ for $30 \mathrm{~s}$. The resulting $\mathrm{C}_{\mathrm{T}}$ values were calculated using the relative standard curve method (Applied Biosystems 2016), in which the $C_{T}$ value of each tested gene was normalized to the $\mathrm{C}_{\mathrm{T}}$ values of recA.

\section{Sequence alignment and generation of phylogenetic trees.}

Protein sequences were aligned using Clustal Omega (Madeira et al. 2019) for visualization. Phylogenetic trees were generated by aligning sequences using MUSCLE (Edgar 2004) and applying the maximum-likelihood method using MEGA $X$ (Kumar et al. 2018), with a Jones-Taylor-Thornton substitution model with uniform rates at all sites, a nearest-neighbor-interchange tree for inference, and bootstrapping with 1,000 replicates to generate consensus trees.

\section{Statistical analyses.}

Total and wilted numbers of leaves were used to calculate the proportion of wilted leaves per plant. Virulence was visually represented as disease progress curves (proportion of leaves wilted over time), which were quantified based on the area under the disease progress curve (AUDPC) as calculated in GraphPad (Prism 9 for Windows). Statistical comparisons were made using GraphPad. AUDPC values were evaluated for a normal distribution with the Shapiro-Wilk test. For two-way comparisons, AUDPC values were subjected to a Student's $t$ test (unpaired, two-tailed, equal variances) with a Welch's correction when the variances were not equal. For multiple comparisons, AUDPC values were subjected to an analysis of variance followed by a Tukey's multiple comparisons test.

\section{LITERATURE CITED}

Applied Biosystems. 2016. Relative quantitation analysis module. Publication no. MAN0014820. Thermo Fisher Scientific Inc., Waltham, MA, U.S.A.

Asselin, J. E., Bonasera, J. M., Kim, J. F., Oh, C.-S., and Beer, S. V. 2011. Eop1 from a Rubus strain of Erwinia amylovora functions as a host-range limiting factor. Phytopathology 101:935-944.

Badel, J. L., Shimizu, R., Oh, H.-S., and Collmer, A. 2006. A Pseudomonas syringae pv. tomato avrE1/hopM1 mutant is severely reduced in growth and lesion formation in tomato. Mol. Plant-Microbe Interact. 19:99-111.

Bae, C., Han, S. W., Song, Y. R., Kim, B. Y., Lee, H.-J., Lee, J.-M., Yeam, I., Heu, S., and Oh, C.-S. 2015. Infection processes of xylemcolonizing pathogenic bacteria: Possible explanations for the scarcity of qualitative disease resistance genes against them in crops. Theor. Appl. Genet. 128:1219-1229.

Bastedo, D. P., Lo, T., Laflamme, B., Desveaux, D., and Guttman, D. S 2020. Diversity and evolution of type III secreted effectors: A case study of three families. Curr. Top. Microbiol. Immunol. 427:201-230.

Bogdanove, A. J., Bauer, D. W., and Beer, S. V. 1998. Erwinia amylovora secretes DspE, a pathogenicity factor and functional AvrE homolog, through the Hrp (type III secretion) pathway. J. Bacteriol. 180:2244-2247

Castiblanco, L. F., Triplett, L. R., and Sundin, G. W. 2018. Regulation of effector delivery by type III secretion chaperone proteins in Erwinia amylovora. Front. Microbiol. 9:146.

Cavanagh, A., Hazzard, R., Adler, L. S., and Boucher, J. 2009. Using trap crops for control of Acalymma vittatum (Coleoptera: Chrysomelidae) reduces insecticide use in butternut squash. J. Econ. Entomol. 102:1101-1107

Chen, C., Malek, A. A., Wargo, M. J., Hogan, D. A., and Beattie, G. A. 2010. The ATP-binding cassette transporter $\mathrm{Cbc}$ (choline/betaine/ carnitine) recruits multiple substrate-binding proteins with strong specificity for distinct quaternary ammonium compounds. Mol. Microbiol. 75:29-45

Cheong, M. S., Kirik, A., Kim, J. G., Frame, K., Kirik, V., and Mudgett, M. B. 2014. AvrBsT acetylates Arabidopsis ACIP1, a protein that associates with microtubules and is required for immunity. PLoS Pathog. 10:e1003952.

Coplin, D. L., Majerczak, D. R., Ham, J.-H., and Mackey, D. 2008. The WtsE virulence effector from Pantoea stewartii, a plant signal mimic? Acta Hortic. 793:203-212.

Datsenko, K. A., and Wanner, B. L. 2000. One-step inactivation of chromosomal genes in Escherichia coli K-12 using PCR products. Proc. Natl. Acad. Sci. U.S.A. 97:6640-6645.

DebRoy, S., Thilmony, R., Kwack, Y. B., Nomura, K., and He, S. Y. 2004. A family of conserved bacterial effectors inhibits salicylic acidmediated basal immunity and promotes disease necrosis in plants. Proc. Natl. Acad. Sci. U.S.A. 101:9927-9932.

Degrave, A., Siamer, S., Boureau, T., and Barny, M.-A. 2015. The AvrE superfamily: Ancestral type III effectors involved in suppression of pathogen-associated molecular pattern-triggered immunity. Mol. Plant Pathol. 16:899-905.

Eckshtain-Levi, N., Munitz, T., Živanović, M., Traore, S. M., Spröer, C., Zhao, B., Welbaum, G., Walcott, R., Sikorski, J., and Burdman, S. 2014. Comparative analysis of type III secreted effector genes reflects divergence of Acidovorax citrulli strains into three distinct lineages. Phytopathology 104:1152-1162.

Edgar, R. C. 2004. MUSCLE: Multiple sequence alignment with high accuracy and high throughput. Nucleic Acids Res. 32:1792-1797.

Eigenbrode, S. D., Bosque-Pérez, N. A., and Davis, T. S. 2018. Insectborne plant pathogens and their vectors: Ecology, evolution, and complex interactions. Annu. Rev. Entomol. 63:169-191.

Gaudriault, S., Malandrin, L., Paulin, J.-P., and Barny, M.-A. 1997. DspA, an essential pathogenicity factor of Erwinia amylovora showing homology with AvrE of Pseudomonas syringae, is secreted via the Hrp secretion pathway in a DspB-dependent way. Mol. Microbiol. 26:1057-1069.

Gaudriault, S., Paulin, J. P., and Barny, M.-A. 2002. The DspB/F protein of Erwinia amylovora is a type III secretion chaperone ensuring 
efficient intrabacterial production of the Hrp-secreted DspA/E pathogenicity factor. Mol. Plant Pathol. 3:313-320.

Guy, E., Genissel, A., Hajri, A., Chabannes, M., David, P., Carrere, S., Lautier, M., Roux, B., Boureau, T., Arlat, M., Poussier, S., and Noël, L. D. 2013. Natural genetic variation of Xanthomonas campestris pv. campestris pathogenicity on Arabidopsis revealed by association and reverse genetics. MBio 4:e00538-12.

Ham, J. H., Majerczak, D. R., Arroyo-Rodriguez, A. S., Mackey, D. M., and Coplin, D. L. 2006. WtsE, an AvrE-family effector protein from Pantoea stewartii subsp. stewartii, causes disease-associated cell death in corn and requires a chaperone protein for stability. Mol. PlantMicrobe Interact. 19:1092-1102.

Heeb, S., Itoh, Y., Nishijyo, T., Schnider, U., Keel, C., Wade, J., Walsh, U., O'Gara, F., and Haas, D. 2000. Small, stable shuttle vectors based on the minimal pVS1 replicon for use in gram-negative, plant-associated bacteria. Mol. Plant-Microbe Interact. 13:232-237.

Hilaire, E., Young, S. A., Willard, L. H., McGee, J. D., Sweat, T., Chittoor, J. M., Guikema, J. A., and Leach, J. E. 2001. Vascular defense responses in rice: Peroxidase accumulation in xylem parenchyma cells and xylem wall thickening. Mol. Plant-Microbe Interact. 14:1411-1419.

Ho, S. N., Hunt, H. D., Horton, R. M., Pullen, J. K., and Pease, L. R. 1989. Site-directed mutagenesis by overlap extension using the polymerase chain reaction. Gene 77:51-59.

Jacobs, J. M., Milling, A., Mitra, R. M., Hogan, C. S., Ailloud, F., Prior, P., and Allen, C. 2013. Ralstonia solanacearum requires PopS, an ancient AvrE-family effector, for virulence and to overcome salicylic acidmediated defenses during tomato pathogenesis. MBio 4:e00875-13.

Jiang, S., Yao, J., Ma, K.-W., Zhou, H., Song, J., He, S. Y., and Ma, W. 2013. Bacterial effector activates jasmonate signaling by directly targeting JAZ transcriptional repressors. PLoS Pathog. 9:e1003715.

Kim, H.-S., Thammarat, P., Lommel, S. A., Hogan, C. S., and Charkowski, A. O. 2011. Pectobacterium carotovorum elicits plant cell death with $\mathrm{DspE} / \mathrm{F}$ but the $P$. carotovorum DspE does not suppress callose or induce expression of plant genes early in plant-microbe interactions. Mol. Plant-Microbe Interact. 24:773-786.

King, E. O., Ward, M. K., and Raney, D. E. 1954. Two simple media for the demonstration of pyocyanin and fluorescin. J. Lab. Clin. Med. 44: 301-307.

Kobayashi, D. Y., Tamaki, S. J., and Keen, N. T. 1989. Cloned avirulence genes from the tomato pathogen Pseudomonas syringae pv. tomato confer cultivar specificity on soybean. Proc. Natl. Acad. Sci. U.S.A. 86:157-161.

Kumar, S., Stecher, G., Li, M., Knyaz, C., and Tamura, K. 2018. MEGA $\mathrm{X}$ : Molecular evolutionary genetics analysis across computing platforms. Mol. Biol. Evol. 35:1547-1549.

Laflamme, B., Dillon, M. M., Martel, A., Almeida, R. N. D., Desveaux, D., and Guttman, D. S. 2020. The pan-genome effector-triggered immunity landscape of a host-pathogen interaction. Science 367:763-768.

Lee, A. H.-Y., Hurley, B., Felsensteiner, C., Yea, C., Ckurshumova, W., Bartetzko, V., Wang, P. W., Quach, V., Lewis, J. D., Liu, Y. C., Börnke, F., Angers, S., Wilde, A., Guttman, D. S., and Desveaux, D. 2012. A bacterial acetyltransferase destroys plant microtubule networks and blocks secretion. PLoS Pathog. 8:e1002523.

Lee, J., Manning, A. J., Wolfgeher, D., Jelenska, J., Cavanaugh, K. A., Xu, H., Fernandez, S. M., Michelmore, R. W., Kron, S. J., and Greenberg, J. T. 2015. Acetylation of an NB-LRR plant immune-effector complex suppresses immunity. Cell Rep. 13:1670-1682.

Le Roux, C., Huet, G., Jauneau, A., Camborde, L., Trémousaygue, D., Kraut, A., Zhou, B., Levaillant, M., Adachi, H., Yoshioka, H., Raffaele, S., Berthomé, R., Couté, Y., Parker, J. E., and Deslandes, L. 2015. A receptor pair with an integrated decoy converts pathogen disabling of transcription factors to immunity. Cell 161:1074-1088.

Liu, Q. 2015. Bacterial wilt of cucurbits: Impact of plant age on symptom progression and pathogen movement and locating genes associated with host preference and pathogenesis in E. tracheiphila. M.S. thesis, Iowa State University.

Liu, Q., Beattie, G. A., Rojas, E. S., and Gleason, M. L. 2018. Bacterial wilt symptoms are impacted by host age and involve net downward movement of Erwinia tracheiphila in muskmelon. Eur. J. Plant Pathol. $151: 803-810$

Ma, K.-W., and Ma, W. 2016. YopJ family effectors promote bacterial infection through a unique acetyltransferase activity. Microbiol. Mol. Biol. Rev. 80:1011-1027

Madeira, F., Park, Y. M., Lee, J., Buso, N., Gur, T., Madhusoodanan, N., Basutkar, P., Tivey, A. R. N., Potter, S. C., Finn, R. D., and Lopez, R. 2019. The EMBL-EBI search and sequence analysis tools APIs in 2019. Nucleic Acids Res. 47:W636-W641.
Mittal, R., Peak-Chew, S. Y., Sade, R. S., Vallis, Y., and McMahon, H. T. 2010. The acetyltransferase activity of the bacterial toxin YopJ of Yersinia is activated by eukaryotic host cell inositol hexakisphosphate. J. Biol. Chem. 285:19927-19934.

Mor, H., Manulis, S., Zuck, M., Nizan, R., Coplin, D. L., and Barash, I. 2001. Genetic organization of the $h r p$ gene cluster and $d s p A E / B F$ operon in Erwinia herbicola pv. gypsophilae. Mol. Plant-Microbe Interact. 14:431-436.

Morris, H., Plavcová, L., Gorai, M., Klepsch, M. M., Kotowska, M., Jochen Schenk, H., and Jansen, S. 2018. Vessel-associated cells in angiosperm xylem: Highly specialized living cells at the symplast-apoplast boundary. Am. J. Bot. 105:151-160.

Nazareno, E. S., and Dumenyo, C. K. 2015. Modified inoculation and disease assessment methods reveal host specificity in Erwinia tracheiphilaCucurbitaceae interactions. Microb. Pathog. 89:184-187.

Oh, C.-S., Kim, J. F., and Beer, S. V. 2005. The Hrp pathogenicity island of Erwinia amylovora and identification of three novel genes required for systemic infection. Mol. Plant Pathol. 6:125-138.

Orth, K., Xu, Z., Mudgett, M. B., Bao, Z. Q., Palmer, L. E., Bliska, J. B., Mangel, W. F., Staskawicz, B., and Dixon, J. E. 2000. Disruption of signaling by Yersinia effector YopJ, a ubiquitin-like protein protease. Science 290:1594-1597.

Peeters, N., Carrère, S., Anisimova, M., Plener, L., Cazalé, A. C., and Genin, S. 2013. Repertoire, unified nomenclature and evolution of the type III effector gene set in the Ralstonia solanacearum species complex. BMC Genomics 14:859.

Pereira, I. C., Badel, J. L., Vidigal, P. M. P., Sousa, A. A., Santos, S. A., Guimarães, L. M. S., and Alfenas, A. C. 2021. Prediction, structure characterization, and evolutionary analysis of Erwinia psidii putative type III effectors. Plant Pathol. 70:555-566.

Rojas, E. S., Batzer, J. C., Beattie, G. A., Fleischer, S. J., Shapiro, L. R., Williams, M. A., Bessin, R., Bruton, B. D., Boucher, T. J., Jesse, L. C. H., and Gleason, M. L. 2015. Bacterial wilt of cucurbits: Resurrecting a classic pathosystem. Plant Dis. 99:564-574.

Rojas, E. S., Dixon, P. M., Batzer, J. C., and Gleason, M. L. 2013. Genetic and virulence variability among Erwinia tracheiphila strains recovered from different cucurbit hosts. Phytopathology 103:900-905.

Sánchez, E. S., Hernández, E., Gleason, M. L., Batzer, J. C., Williams, M. A., Coolong, T., and Bessin, R. 2015. Optimizing rowcover deployment for managing bacterial wilt and using compost for organic muskmelon production. HortTechnology 25:762-768.

Sarris, P. F., Duxbury, Z., Huh, S. U., Ma, Y., Segonzac, C., Sklenar, J., Derbyshire, P., Cevik, V., Rallapalli, G., Saucet, S. B., Wirthmueller, L., Menke, F. L. H., Sohn, K. H., and Jones, J. D. G. 2015. A plant immune receptor detects pathogen effectors that target WRKY transcription factors. Cell 161:1089-1100.

Schreiber, K. J., Chau-Ly, I. J., and Lewis, J. D. 2021. What the wild things do: Mechanisms of plant host manipulation by bacterial type III-secreted effector proteins. Microorganisms 9:1029.

Shapiro, L. R., Paulson, J. N., Arnold, B. J., Scully, E. D., Zhaxybayeva, O., Pierce, N. E., Rocha, J., Klepac-Ceraj, V., Holton, K., and Kolter, R. 2018. An introduced crop plant is driving diversification of the virulent bacterial pathogen Erwinia tracheiphila. MBio 9:e01307-18.

Siamer, S., Gaubert, S., Boureau, T., Brisset, M.-N., and Barny, M.-A 2013. Mutational analysis of a predicted double $\beta$-propeller domain of the DspA/E effector of Erwinia amylovora. FEMS Microbiol. Lett. 342:54-61.

Smith, E. 1911. Bacteria in Relation to Plant Diseases. Carnegie Institution of Washington, Washington, D.C., U.S.A.

Triplett, L., Melotto, M., He, S. Y., and Sundin, G. 2008. Translocation and chaperone interaction of the Erwinia amylovora secreted effector DspE. Acta Hortic. 793:231-236.

Vrisman, C. M., Deblais, L., Rajashekara, G., and Miller, S. A. 2016 Differential colonization dynamics of cucurbit hosts by Erwinia tracheiphila. Phytopathology 106:684-692.

Walcott, R. R., Fessehaie, A., and Castro, A. C. 2004. Differences in pathogenicity between two genetically distinct groups of Acidovorax avenae subsp. citrulli on cucurbit hosts. J. Phytopathol. 152:277-285.

Weber, D. C. 2018. Field attraction of striped cucumber beetles to a synthetic vittatalactone mixture. J. Econ. Entomol. 111:2988-2991.

Wöhner, T. W., Richter, K., Sundin, G. W., Zhao, Y., Stockwell, V. O., Sellmann, J., Flachowsky, H., Hanke, M.-V., and Peil, A. 2018. Inoculation of Malus genotypes with a set of Erwinia amylovora strains indicates a gene-for-gene relationship between the effector gene eopl and both Malus floribunda 821 and Malus 'Evereste'. Plant Pathol 67:938-947. 
Wu, L., McGrane, R. S., and Beattie, G. A. 2013. Light regulation of swarming motility in Pseudomonas syringae integrates signaling pathways mediated by a bacteriophytochrome and a LOV protein. MBio 4:e00334-13.

Xin, X. F., Nomura, K., Aung, K., Velásquez, A. C., Yao, J., Boutrot, F., Chang, J. H., Zipfel, C., and He, S. Y. 2016. Bacteria establish an aqueous living space in plants crucial for virulence. Nature 539:524-529.
Yadeta, K. A., and Thomma, B. P. H. J. 2013. The xylem as battleground for plant hosts and vascular wilt pathogens. Front. Plant Sci. 4:97.

Yuan, X. C., Hulin, M. T., and Sundin, G. W. 2020. Effectors, chaperones, and harpins of the type III secretion system in the fire blight pathogen Erwinia amylovora: A review. J. Plant Pathol. 103: 25-39. 